\section{Tootsie afoot?}

Stephen Lock

The Health Conspiracy: How Doctors, the Drug Industry and the Government Undermine Our Health. By Joe Collier. Century Hutchinson, London: 1989. Pp.175. Pbk £4.95.

"Practically none of the great therapeutic advances has come from practising doctors or departments of clinical research" - that contention is as true today as when it was first made 20 years ago by Lord Platt, a professor of medicine and president of the Royal College of Physicians. Yet fortunately, since the therapeutic revolution began with the sulphonamides in the $1930 \mathrm{~s}$, the pharmaceutical industry has developed a massive armament of drugs against common disease, including not only the antibiotics but treatments for peptic ulcers, raised blood pressure, heart disease, asthma, diabetes, Parkinson's disease and schizophrenia.

At the same time all of us have been uneasily aware of the negative aspect of this success story - the inescapable sideeffects of many drugs (some horrendous) and the sleazy way in which some drugs have been promoted. In Britain, and elsewhere, has this difficult balance now tilted the wrong way? It is Joe Collier's contention that it has: not only is the pharmaceutical industry becoming less innovative as research is increasingly diverted to commercial ends, but there is a conspiracy by "rich and privileged forces" who are denying patients the treatment they need.

\section{Prejudice}

To be sure, Collier, an academic clinical pharmacologist who works in London, phrases the last claim as a question. But he leaves us in little doubt about his own answer. As part of the rich and privileged forces, British doctors are failing their patients. Not only are their judgements contaminated by prejudices - those of class, sex and race - but they have lost their touch and can no longer make diagnoses with confidence. Rather than tackle the root causes of illness, or use supportive treatment, they keep patients at arm's length, reflexly reaching for the prescription pad. And they are in the pocket of the drug industry, now the dominant influence on medical practice. Casting its net wide, not only does the industry spend $£ 140$ million a year on drug promotion - including gifts to doctors but some of its so-called research expenditure includes bogus drug trials - postmarketing surveillance designed so that family doctors prescribe the drug under study - and seminars that are barely concealed public relations exercises.

All this is stark stuff, though Collier is careful to document most of his allegations. Yet there is a third conspirator in his indictment: the British government. At the heart of The Health Conspiracy is the CSM, the Committee on Safety of Medicines, which arose out of the public anguish over the thalidomide affair. Today, obtaining a licence for a new drug may take up to 12 years of a 20-year patent life, and the members of the CSM, who take the decision, may have to assess (literally) a lorry load of data. Yet they are concerned with safety and not efficacy (which is the remit of another committee), and moreover with balancing the risks of a drug against the dangers of the disease. It is their task to monitor the safety of a drug after it has been licensed, but that process is inevitably imperfect and tragic instances of unsuspected lethal side-effects still make the headlines.

Collier concedes that, worldwide, the CSM has been one of the most successful regulatory agencies but argues that it is hamstrung in three major ways. First, its composition, with five members from the drug industry and several medical academics with paid consultancies, raises questions of conflicts of interest. Second, its restricted concern with safety means that it is flooded with applications to license look-alike drugs which have no advantages over those already on the market. Third, given that it is part of the Department of Health's Medicines Division, not only is it caught up in the national obsession for secrecy about almost everything, but there is also a "hopelessly conflicting" contradiction in the department's dual role of regulating drugs, on the one hand, and promoting a successful international drug industry on the other.

An eminently readable book, The Health Conspiracy deals well with its subject. There is a succinct account of the complexities of drug licensing as well as side-swipes about smoking, alcohol, screening for cervical and breast cancer, and the Black Report of 1980 , Inequalities in Health. Collier also offers solutions to the main problems. Principally, a new alliance between patients and providers is needed. Scientists in the drug industry must remember that their first duty is to science, while marketing and promotion staff must ensure that advertisements are honest. The government should divorce the two functions of the Medicines Division, transferring the promotional side to the Department of Trade; revise the Medicines Act to ensure openness and an emphasis on efficacy; and establish a list of patients' rights, including no-fault compensation. Doctors must become more vigilant in dealing with the industry and reform their training. Patients must take a more active role in their own treatment by asserting their rights.

Although a recent White Paper on the future of the National Health Service has made a few of Collier's facts out of date, most of them are right; it is his interpretation of them that I find more difficult (and here I should declare an interest in editing a journal that is partially funded by pharmaceutical advertisements).

\section{Idealism}

Collier is evidently an idealist. Part of his dissatisfaction, it seems to me, stems from disenchantment with human nature, part from a dislike of specific features of British life. No society has found a better mechanism than capitalism for developing new ideas - how many valuable drugs have come out of the Eastern bloc countries? - and capitalism entails an inevitable tension between purity and commerce. In Britain, moreover, there has long been a syndrome of dolce far niente, which has been tolerated by successive generations and governments of all complexions. As well as those described by Collier, its features include variously the low fraction of gross national product devoted to the National Health Service, the low proportion of school leavers receiving higher education, the Official Secrets Act, overcrowding in prisons, and the tower blocks on the Aylesbury estate. To these we can add the tootsie-footsie relationship between doctors and the pharmaceutical industry.

All this is not to say that several aspects of the pharmaceutical industry are not distasteful, or even dishonest, and eventually most of them will have to be put right (as has happened in the Nordic countries). But in life you are either liberal with Locke or coercive with Hobbes, and my personal preference is for the former. Part of my fears of excessive reform stem from the certainty of those who recommend it, and the possibility that individual clinical decisions will come to be made by diktat.

Thus I am dismayed by one feature of a publication that Collier commends - the Drug and Therapeutics Bulletin - and that is censorship. Sent by the Department of Health free to every general practitioner in England and Wales, the Bulletin is a valuable summary of the uses, side effects and contraindications of drugs old and new. It is written by anonymous experts and extensively reviewed before publication. Yet it has no mechanism for debate; it publishes no correspondence and only the occasional correction of fact; all this on subjects where there can be no certainty without the widest discussion. Open debate is, I believe, still the one big plus in our society. We should hesitate before destroying the creativity of the pharmaceutical industry. And that, I suspect, would be the result if Collier's suggestions were implemented.

Stephen Lock is Editor of the British Medical Journal, BMA House, Tavistock Square, London WC1H 9JR, UK. 